\title{
Relationship between obesity and frailty in an old age population of Sindh, Pakistan
}

\author{
Kainat Faizan ${ }^{1}$ and Aadil Ameer Ali ${ }^{2 *}$ \\ 'Bahria University College of Physical Therapy, Bahria University of Medical and Dental College \\ Karachi, Pakistan \\ ${ }^{2}$ Institute of Physiotherapy \& Rehabilitation Sciences, Shaheed Mohtarma Benazir Bhutto Medical \\ University, Larkana, Pakistan
}

Received: 13 July, 2021

Accepted: 23 July, 2021

Published: 24 July, 2021

*Corresponding author: Dr Aadil Ameer Ali, Institute of Physiotherapy \& Rehabilitation Sciences, Shaheed Mohtarma Benazir Bhutto Medical University, Larkana, Pakistan, Tel: +923002929464; E-mail: aadilamirali@hotmail.com

Keywords: Obesity; Fraility; Old people; Sindh; Pakistan

https://www.peertechzpublications.com

Check for updates

\section{Abstract}

Objective: To identify the Relationship between Obesity and Frailty in an old age Population of Sindh, Pakistan.

Methodology: A cross sectional survey was conducted in many different hospitals of Karachi, Pakistan in December 2017. A self-constructed questionnaire was used which includes which includes the demographics, health status of patients, the Body Mass Index (BMI) and to analyze the data acquired, we used SPSS version 23.

Results: $89.1 \%(n=339)$ of the participants belong to age group of $60-65$ years and $57.3 \%(n=216)$ were male. Moreover, the Majority ( $n=183$, $78.8 \%)$ of the participants reported with poor health status. After checking the level of Frailty among the participants, $(n=218,58 \%)$ of the participants were found to be frail.

Conclusion: This Study concluded that there is significant impact of obesity on Frailty, because as the people ages the level of calcium and vitamin D in the bones decreases, bone become fragile and cannot support the increased weight of an individual which leads to weakness and susceptibility to disease.

\section{Introduction}

Obesity is defined as an abnormal gathering of muscle versus fat, typically $20 \%$ or more over a person's optimal body weight. Obesity is related with the expanded danger of incapacity, disease and ultimately; demise. The reasons for obesity are characterized as; taking an excessive number of calories, living a sedentary lifestyle, not getting enough sleep, nutriment that causes disruption of endocrine function, drugs that have side effects causing weight gain, and genetic variation from one person to another resulting in a higher BMR in some and lower in others. Obesity can be prevented by following healthy diet plans, keeping track of the number of calories you consume, being active, and maintaining a healthy weight according to your BMI. Currently, the proportion of 60 years and older worldwide is estimated at 12 percent, and it is increasing rapidly and is estimated to reach 21 percent by 2050 . In more established regions, this proportion is predictable to reach 32 percent in 2050. However, a large proportion of senior citizens will undergo chronic conditions or disability, decreased physical capacity, with declining cognitive function, and will engage less in life due to multiple mechanisms of aging derived from environmental and genetic factors. Patients who developed diseases as they aged present the most challenging and complex problems to all health care professionals.

Frailty is defined as a clinical syndrome in which three or more of the following criteria is present: self-reported exhaustion, unintentional weight loss (10 lbs in past year), slow walking speed, weakness (grip strength) and low physical activity. Frailty among older people is a geriatric clinical disorder that incorporates a physiological condition of intensified weakness to stressors that outcome in diminished physiological stores and liberation of various frameworks. It is upheld by a triad of changes identified with the maturing interaction: sarcopenia, neuroendocrine liberation, and immune system dysfunction. It is reported in many different studies that obesity is a confounding factor in frailty. If a person 
wants to prevent themselves from frailty in their advanced years, then he or she must exercise every day and try to stay active. Organizing activities as indicated by an individual's capacities. Walking/jogging is helpful to maintain a healthy heart, equilibrium, and bulk. Activities utilizing opposition, for example, lifting loads shape muscle and help to diminish joint firmness and pain. Indeed, even little expansions in wellness can further develop side effects of frailty [1-6].

\section{Materials and methods}

\section{Study design, settings and duration}

A cross sectional descriptive study was conducted from June to August 2018, and data was collected from different areas of Hyderabad, Tando Kaysar, Mirpurkhas, Tando Muhammad Khan, Badeen, Matyari, Matli, Hala, Hingorja, Kot Diji, Mithi, Badin, Khipro \& Karachi, Pakistan.

\section{Sampling}

Convenient Non-Probability Sampling Technique among the 377 selected participants was used. Participants of both genders (male and female), obese, and aged above 60 years, who were willing to participate, were included in this study. Whereas participants aged less than 60 years, having any disease, unable to stand and unwilling to sign a consent form were excluded from the study.

\section{Data collection tool}

A self-constructed proforma was used to collect the data, which included the demographic Characterstics age and gender. While the questions related to frailty required the participant to rate whether "Not frail", "Intermediate frail" and "Frail". The patients were categorized into these three classes by asking participants and comparing answers related to their activities of daily life.

\section{Data collection procedure}

The participants were asked to fill the questionnaire on the spot, only the minor help was given upon the request of participants in order to understand the questionnaire.

\section{Data analysis procedure}

Descriptive statistics; categorical variables were measured as frequency and percentage where the data was analyzed by using Statistical Package for Social Sciences (SPSS) version 23.

\section{Ethical concern}

The Ethical approval was taken from the Review Committee of Isra University Karachi, Pakistan and for data collection prior permission was taken from participants. Informed consent was taken from the participants prior to the data collection that their participation is voluntary, and that information of their responses will be kept confidential and they were also informed that they could leave the study any time they wanted.

\section{Results}

Table 1 displays demographic characteristics of participants. Majority ( $n=339,89.1 \%$ ) of the participants belongs to to age group of $60-65$ years and $(n=216,57.3 \%)$ were male.

Table 2 displays Health Status of participants. Majority $(n=183,78.8 \%)$ of the participants reported with poor health status followed by $(n=95,30.2 \%)$ with good status.

Table 3 displays Level of Frailty among the participants. Majority $(n=218,58 \%)$ of the participants were found frail followed by $(n=136,36 \%)$ intermediate fragility.

Table 4 Correlation between Obesity and Frailty showed in Table 4 and concluded that there is significant relationship between the obesity and Frailty.

\section{Discussion}

In this study we found that obesity has a direct relation with the frailty among older adults. Most of the obese participants were found frail and those obese persons were not able to perform their daily routine activities. Obesity is an unusual gathering of muscle versus fat, generally $20 \%$ or more over a person's optimal body weight. Obesity is related with extended

\begin{tabular}{|c|c|c|}
\hline Table 1: Demographic characteristics. \\
\hline Demographics & Frequency $(\boldsymbol{n}=\mathbf{3 7 7})$ & Percentage $\%=\mathbf{1 0 0 . 0}$ \\
\hline Age & 89.1 \\
\hline 66 and above years & 339 & 10.1 \\
\hline & 38 & \\
\hline Male & Gender & 57.3 \\
\hline Female & 216 & 42.7 \\
\hline
\end{tabular}

Table 2: Health status.

\begin{tabular}{|c|c|c|}
\hline Health Status & Frequency $(\boldsymbol{n = 3 7 7})$ & Percentage $\%=\mathbf{1 0 0 . 0}$ \\
\hline Excellent & 08 & 2.1 \\
\hline Very Good & 11 & 1.3 \\
\hline Good & 95 & 25.1 \\
\hline Poor & 263 & 69.7 \\
\hline
\end{tabular}

Table 3: Level of Fraility.

\begin{tabular}{|c|c|c|}
\hline Characterstics & Frequency $(\boldsymbol{n = 3 7 7})$ & Percentage $\% \mathbf{= 1 0 0 . 0}$ \\
\hline Not frail & 23 & 06 \\
\hline Intermediate frail & 136 & 36 \\
\hline Frail & 218 & 58 \\
\hline
\end{tabular}

Table 4: Correlation between obesity and fraility.

\begin{tabular}{|c|c|c|c|c|}
\hline Variable & Not frail & \multicolumn{1}{c|}{ Intermediate frail } & Frail & P-value \\
\hline \multicolumn{4}{|c|}{ Obesity } \\
\hline Normal & 23 & 00 & 00 & \\
\hline Over Weight & 00 & 136 & 00 & 0.003 \\
\hline Obese & 00 & 00 & 218 & \\
\hline
\end{tabular}


risk of illness, debilitation, and downfall. The reason of obesity is to taking too many calories, spending a sedentary lifestyle, not sleeping enough, endocrine disruptors, such as some foods that interfere with lipid metabolism, those medications which puts on weight. Obesity is strongly associated with several major health risk factors. Frailty was found as a clinical syndrome in which following factors were present: self-reported exhaustion, slow walking speed, weakness (grip strength) and low physical activity. In this study most of frail participants were found weak, stressful and low physical active, most of time they were not feeling good, and not able to perform effectively their daily life routine activities [6-11].

Frailty among older people was also found as a geriatric clinical disorder that incorporates a physiological condition of enhanced weakness to stressors because of their diminished disorder, physiological stores and liberation of various frameworks. It is upheld by a group of three of changes identified with the maturing cycle: sarcopenia, neuroendocrine liberation, and resistant framework brokenness. Slightness is viewed as an indicator of antagonistic results, for example, comorbidities, falls, the utilization of medical care administrations, ailments, systematization, disability, adverse consequence on personal satisfaction, mortality, and its predominance is especially pertinent for the field of general wellbeing. Suggestions for weight reduction in corpulent more established grown-ups that limit the probability of unfavourable impacts on bulk, bone thickness, or different parts of healthful status are surveyed. The females were more obese as compare to men $(43.7 \%$ VS $37.6 \%$ ). Frailty is common in later stages of life, but different operationalization of frailty status results in widely differing prevalence between studies $[4,12]$. Vitamin D insufficiency was also found significantly associated with frailty in men, but not in women. Results suggest that PTH mediates the relationship between $25(\mathrm{OH}) \mathrm{D}$ and no energy expenditure aspects of frailty. Chronic CMV (Cytomegalovirus) infection is associated with prevalent frailty, a state with increased morbidity and mortality in older adults; inflammation enhances this effect. Frailty in older men is associated with poorer health and a greater risk of mortality [3,4,13-17].

\section{Conclusion}

This study concluded that Obesity is found as one of the major contributing factor for frailty among older peoples, therefore old age individuals should perform exercise on daily bases in order to avoid the Frailty. Moreover the older individuals should monitor their diet and plan an and plan to stay active during the day to prevent weakness and disability which keep themselves physically active accordingly.

\section{Recommendation}

Weekly or monthly motivational or exercise activity program should be organized by health care providers. Proper walking and exercise facility should be provide by the government to reduce the problem of obesity and frailty among old age people. Government should organize workshops, seminars and other awareness programs to inform senior citizens of the risks of being obese and frail, which may lead to severe complications.

\section{Acknowledgements}

We acknowledge the support of participants who volunteered themselves for data collection.

\section{Author contributions}

Both authors contributed equally.

\section{References}

1. Kasiske BL, O'Donnell MP, Keane WFJH (1992) The Zucker rat model of obesity, insulin resistance, hyperlipidemia, and renal injury. Hypertension 19: 1110-115. Link: https://bit.ly/3wUfLMx

2. Fried LP, Ferrucci L, Darer J, Williamson JD, Anderson G (2004) Untangling the concepts of disability, frailty, and comorbidity: implications for improved targeting and care. J Gerontol A Biol Sci Med Sci 59: M255-M63. Link: https://bit.ly/36XrrDI

3. Juma S, Taabazuing MM, Montero-Odasso MJ (2016) Clinical frailty scale in an acute medicine unit: a simple tool that predicts length of stay. Can Geriatr J 19: 34-39. Link: https://bit.ly/3x1Bq5c

4. Kressig RW, Wolf SL, Sattin RW, O'Grady M, Greenspan A, et al. (2001) Associations of demographic, functional, and behavioral characteristics with activity-related fear of falling among older adults transitioning to frailty. J Am Geriatr Soc 49: 1456-162. Link: https://bit.ly/3xZBsvV

5. Mokdad AH, Ford ES, Bowman BA, Dietz WH, Vinicor F, et al. (2003) Prevalence of obesity, diabetes, and obesity-related health risk factors, 2001. JAMA 289: 76-79. Link: https://bit.ly/3zrtPP1

6. Rubinstein RL, de Medeiros K (2015) "Successful aging," gerontological theory and neoliberalism: A qualitative critique. Gerontologist 55: 34-42. Link: https://bit.ly/3x4cBFU

7. Ali AA, Haq N, Hussain A, Rafique M, Muhammad Ishaque MI, et al. (2021) Assessment of Frequent Work Related Musculoskeletal Disorders in Patients Visiting the Physiothrapy OPD of Civil Hospital Quetta, Pakistan: A Cross Sectional Survey. Indian Journal of Physiotherapy \& Occupational Therapy 15 : 91. Link: https://bit.ly/3eMFD6J

8. Bharathi R, Baby DJaqjdtroa. Rockwood K, Stadnyk K, MacKnight C, McDowell I, Hebert R, Hogan DB (1999). A brief clinical instrument to classify frailty in elderly people. Lancet 353: 205-206.

9. Stevens JA, Corso PS, Finkelstein EA, Miller TR (2006) The costs of fatal and non-fatal falls among older adults. Inj Prev 12: 290-295. Link: https://bit.ly/2V5488j

10. Syddall H, Roberts HC, Evandrou M, Cooper C, Bergman H, et al. (2010) Prevalence and correlates of frailty among community-dwelling older men and women: findings from the Hertfordshire Cohort Study. Age Ageing 39: 197203. Link: https://bit.ly/3kJLhu8

11. Villareal DT, Banks M, Sinacore DR, Siener C, Klein S (2006) Effect of weight loss and exercise on frailty in obese older adults. Arch Intern Med 166: 860866. Link: https://bit.ly/3iD69Rc

12. Buttery AK, Busch MA, Gaertner B, Scheidt-Nave C, Fuchs J (2015) Prevalence and correlates of frailty among older adults: findings from the German health interview and examination survey. BMC Geriatr 15: 22. Link: https://bit.ly/3kMDThz

13. Collard RM, Boter H, Schoevers RA, Oude Voshaar RC (2012) Prevalence of frailty in community-dwelling older persons: a systematic review. J Am Geriatr Soc 60: 1487-1492. Link: https://bit.ly/2TvHaXr 
14. Ali AA, Haq N, Chang K, Naqi S, Rafique M, et al. (2019) Impact of obesity on frailty in older population of Karachi, Pakistan. Advances in Medical, Dental and Health Sciences 2. Link: https://bit.ly/3rszmCn

15. Ashwell M, Hsieh SD (2005) Six reasons why the waist-to-height ratio is a rapid and effective global indicator for health risks of obesity and how its use could simplify the international public health message on obesity. Int J Food Sci Nutr 56: 303-307. Link: https://bit.ly/3BuESZI
16. Rolfson DB, Majumdar SR, Tsuyuki RT, Tahir A, Rockwood K (2006) Validity and reliability of the Edmonton Frail Scale. Age Ageing 35: 526-529. Link: https://bit.ly/3rrbTSO

17. Witkos M, Uttaburanont M, Lang CD, Arora R (2008) Costs of and reasons for obesity. J Cardiometab Syndr 3: 173-176. Link: https://bit.ly/3rBxkzN

\section{Discover a bigger Impact and Visibility of your article publication with}

\section{Peertechz Publications}

\section{Highlights}

- Signatory publisher of ORCID

* Signatory Publisher of DORA (San Francisco Declaration on Research Assessment)

* Articles archived in worlds' renowned service providers such as Portico, CNKI, AGRIS, TDNet, Base (Bielefeld University Library), CrossRef, Scilit, J-Gate etc.

* Journals indexed in ICMJE, SHERPA/ROMEO, Google Scholar etc.

* OAI-PMH (Open Archives Initiative Protocol for Metadata Harvesting)

* Dedicated Editorial Board for every journal

* Accurate and rapid peer-review process

* Increased citations of published articles through promotions

* Reduced timeline for article publication

Submit your articles and experience a new surge in publication services (https://www.peertechz.com/submission).

Peertechz journals wishes everlasting success in your every endeavours.

Copyright: @ 2021 Faizan K, et al. This is an open-access article distributed under the terms of the Creative Commons Attribution License, which permits unrestricted use distribution, and reproduction in any medium, provided the original author and source are credited.

Citation: Faizan K, Ali AA (2021) Relationship between obesity and frailty in an old age population of Sindh, Pakistan. Glob J Obes Diabetes Metab Syndr 8(1): 006 009. DOI: https://dx.doi.org/10.17352/2455-8583.000050 